\title{
DEMANDA DE TRAÇÃO EM HASTE SULCADORA NA INTEGRAÇÃO LAVOURA- PECUÁRIA COM DIFERENTES PRESSÕES DE PASTEJO E SUA RELAÇÃO COM O ESTADO DE COMPACTAÇÃO DO SOLO ${ }^{1}$
}

\author{
OSMAR CONTE ${ }^{2}$, RENATO LEVIEN ${ }^{3}$, CARLOS R. TREIN ${ }^{4}$, CARLA T. C. CEPIK ${ }^{4}$, \\ HENRIQUE DEBIASI ${ }^{5}$
}

\begin{abstract}
RESUMO: Conduziu-se um experimento com integração lavoura-pecuária em Latossolo Vermelho distroférrico para avaliar o esforço de tração em hastes sulcadoras de adubo utilizadas em semeadura direta, atuando em diferentes profundidades e intensidades de pastejo, bem como o efeito desse último fator sobre o estado de compactação do solo. Os tratamentos principais foram constituídos pelas alturas da pastagem de inverno (aveia + azevém): 0,10;0,20;0,30 e 0,40 m e sem pastejo, obtidas variando-se a carga animal, e os tratamentos secundários foram duas profundidades de atuação da haste sulcadora de adubo: 0,12 e 0,15 m. A massa seca de raízes da pastagem, na camada de 0 a $0,12 \mathrm{~m}$, aumentou com o incremento na intensidade de pastejo. Analisando os valores de resistência mecânica do solo à penetração, o efeito do pastejo foi detectado até $0,12 \mathrm{~m}$, sendo crescentes com a intensidade de pastejo. A força de tração demandada pelas hastes aumentou de 1.900 para $4.300 \mathrm{~N}$ (120\%), quando a profundidade de trabalho passou de 0,12 para $0,15 \mathrm{~m}$. O esforço de tração nas hastes sulcadoras também foi maior quanto maior a carga de animais sobre a pastagem, embora as diferenças tenham sido significativas apenas entre os tratamentos sem pastejo e os mantidos a alturas de 0,10 e $0,20 \mathrm{~m}$. Os valores de resistência do solo à penetração e de esforço de tração demandado pelas hastes sulcadoras apresentaram correlação significativa.
\end{abstract}

PALAVRAS-CHAVE: semeadura direta, semeadora-adubadora, mecanismo sulcador.

\section{DRAFT REQUIREMENT IN DIRECT DRILLING IN CROP AND CATTLE ROTATION SYSTEMS USING DIFFERENT GRAZING PRESSURES AND ITS RELATION TO SOIL COMPACTNESS STATUS}

\begin{abstract}
An experiment was carried out with crop and cattle rotation in an Oxisoil, in Tupanciretã - RS, which aimed to evaluate the draft effort in fertilizer direct drillings used in direct seeding, working at different depths and intensities of fields under different grazing pressures. Grazing pressure effects on soil compactness were also assessed. The main treatments were grazing maintaining $0.10,0.20,0.30,0.40 \mathrm{~m}$ pasture (Lolium multiflorum + Avena strigosa) without grazing, height (adjusting the number of cows on the plots) and two working depths of fertilizer shanks: $0.12 \mathrm{~m}$ and $0.15 \mathrm{~m}$. Root dry matter in the superficial layer $(0.0-0.12 \mathrm{~m})$ was increased when higher grazing pressures were used. Soil resistance to a penetrometer showed increased values at higher grazing pressures; it was detected until $0.12 \mathrm{~m}$ depth. Draft requirement of fertilizer shanks increased from 1,900 to $4,300 \mathrm{~N}(120 \%)$ when the working depth changed from $0.12 \mathrm{~m}$ to $0.15 \mathrm{~m}$ condition. Draft demand by fertilizer shanks was higher on soils under higher pressures as well, but the absolute values showed that only treatments with remaining heights of 0.10 and $0.20 \mathrm{~m}$ were different from those found without grazing systems. Soil resistance to penetrometer and power demand by fertilizer shanks was closely related.
\end{abstract}

KEYWORDS: no tillage, seed drill, furrow opener.

\footnotetext{
${ }^{1}$ Pesquisa financiada com recursos do CNPq.

${ }^{2}$ Eng $^{\mathrm{o}}$ Agrônomo, mestrando do Programa de Pós-Graduação em Ciência do Solo/UFRGS, Área de Mecanização Agrícola, Faculdade de Agronomia/UFRGS, Av. Bento Gonçalves, 7712, Porto Alegre - RS. agroconte@ yahoo.com.br

${ }^{3}$ Eng $^{\mathrm{o}}$ Agrônomo, Professor Adjunto, Departamento de Solos, Faculdade de Agronomia/UFRGS, Porto Alegre - RS.

${ }^{4}$ Eng $^{\mathbf{a}}$ Agrícola, doutoranda em Ciência do Solo, Área de Mecanização Agrícola, UFRGS, Porto Alegre - RS.

${ }^{5}$ Eng ${ }^{0}$ Agrônomo, doutorando em Ciência do Solo, Área de Mecanização Agrícola, UFRGS, Porto Alegre - RS.

Recebido pelo Conselho Editorial em: 6-10-2006
}

Aprovado pelo Conselho Editorial em: 19-1-2007 


\section{INTRODUÇÃO}

Na integração lavoura-pecuária (ILP), onde as áreas de produção são intensamente usadas, o sistema deve ser otimizado, com a busca da melhor combinação de manejo e gerenciamento das atividades, tanto no verão como no inverno, de forma que a produção animal não prejudique a produção de grãos e vice-versa. Numa primeira etapa, o pastejo resulta no desfolhamento da pastagem e a conseqüente perda da cobertura vegetal; ao mesmo tempo, tem-se a aplicação de tensões ao solo por meio do pisoteio animal (TABOADA, 2005). Isso pode resultar em aumento da perda de água por evaporação e na compactação do solo, que se constitui numa das principais causas da degradação da capacidade produtiva de solos agrícolas (ALBUQUERQUE et al., 2001). De maneira geral, pode-se dizer que todos os solos sob pastejo sofrem compactação devido ao tráfego dos animais, sobretudo os solos argilosos quando úmidos (TREIN et al., 1991; CORREA \& REICHARDT, 1995; FLORES, 2004) ou quando são utilizadas intensidades de pastejo demasiadamente altas (BERTOL et al., 1998; BERTOL et al., 2000).

Os efeitos da compactação sobre as propriedades físicas do solo têm sido claramente demonstrados. DIAS JÚNIOR \& PIERCE (1996) afirmam que a compactação aumenta a densidade do solo e a resistência mecânica e diminui a porosidade total em função, principalmente da redução no volume de macroporos. No que se refere ao desenvolvimento das plantas, os maiores prejuízos parecem estar relacionados às relações hídricas e de aeração do solo, bem como ao aumento da resistência do solo à penetração das raízes (IMHOFF, 2002; LEÃO, 2002). Foi provado que o aumento da compactação modifica as curvas características de água no solo e reduz a condutividade hidráulica do mesmo, diminuindo a disponibilidade de água às plantas (DEXTER, 2004). Valores de porosidade de aeração abaixo do nível considerado crítico (10\%), por sua vez, são atingidos sob menores teores de água (IMHOFF, 2002). Tanto a deficiência de oxigênio (HILLEL, 1982) quanto a elevada resistência à penetração (ROSOLEM et al., 2002; BEUTLER \& CENTURION, 2004) diminuem o crescimento e a efetividade das raízes, afetando negativamente a absorção de nutrientes e água. A deficiência de $\mathrm{O}_{2}$ também afeta negativamente a biota do solo, levando à menor ciclagem dos nutrientes presentes nos resíduos vegetais e animais (SOUSA et al., 2006).

O pisoteio animal, gerando compactação do solo, possivelmente interfere nas relações que se estabelecem entre as hastes sulcadoras de adubo usadas em semeadura direta e o solo, podendo aumentar a força de tração requerida pelas mesmas. Nesse sentido, o esforço de tração exigido nas hastes depende das características construtivas, como ângulo de ataque, largura da ponteira e formato, espessura e ângulo de inclinação da haste (SÁNCHEZ-GIRÓN et al., 2005). Além disso, este parâmetro aumenta com o incremento da profundidade de trabalho (LEVIEN, 1999) e da resistência do solo ao cisalhamento (SÁNCHEZ-GIRÓN, 1996). A resistência ao cisalhamento é proporcional à coesão e ao ângulo de atrito interno do solo, e a magnitude dessas variáveis é maior em solos compactados (SECCO, 2003). Assim, incrementos na demanda de força de tração de hastes sulcadoras em função da compactação do solo são esperados e foram relatados em trabalhos como os realizados por TULLBERG (2000) e SANCHEZ-GIRÓN et al. (2005). No entanto, são poucos os trabalhos realizados com o intuito de verificar se o pisoteio animal é capaz de compactar o solo ao ponto de refletir em aumentos na demanda de força de tração das hastes sulcadoras de adubo.

Com base no que foi exposto, este trabalho partiu da hipótese de que o aumento na intensidade de pastejo, ou seja, da carga animal por área, resulta em maior compactação superficial e em menores teores de água no solo. Em consequiência, a força de tração demandada pelas hastes sulcadoras de adubo, em semeadura direta, aumenta. Este estudo teve por objetivo quantificar o esforço de tração de hastes sulcadoras de adubo usadas em semeadura direta em função da profundidade de atuação das mesmas e da intensidade de pastejo, bem como o efeito desse último fator sobre o estado de compactação do solo. 


\section{MATERIAL E MÉTODOS}

O experimento foi conduzido desde 2001, na Fazenda Cerro Coroado, município de Tupanciretã - RS, região fisiográfica do Planalto Médio, tendo a localização geográfica designada pela latitude $29^{\circ} 03^{\prime} 10^{\prime \prime}$ 'sul e longitude $53^{\circ} 50^{\prime} 44^{\prime \prime}$ 'oeste, à altitude de $465 \mathrm{~m}$. O solo foi classificado como Latossolo Vermelho distroférrico, unidade de mapeamento Santo Ângelo (EMBRAPA, 1999), possuindo $540 \mathrm{~g} \mathrm{~kg}^{-1}$ de argila. A área experimental, conduzida desde 1994 sob semeadura direta de soja no verão, e aveia-preta no inverno, possui cerca de 22 ha e foi dividida em 14 parcelas, com diferentes tamanhos.

O experimento constituiu-se de um bifatorial conduzido sob o delineamento experimental de blocos casualizados, com três repetições para as alturas de pastagem e duas para sem pastejo (SP). Os tratamentos constaram de cinco intensidades de pastejo representadas por quatro alturas da pastagem $(0,10 ; 0,20 ; 0,30$ e $0,40 \mathrm{~m}$ e sem pastejo - SP), e duas profundidades de atuação da haste sulcadora de adubo: $0,12 \mathrm{~m}$ e $0,15 \mathrm{~m}$. Foram utilizados três animais-teste por parcela, juntamente com número variável de animais reguladores, que foram adicionados ou retirados das referidas parcelas visando à manutenção das alturas de pastejo propostas.

A demanda de tração das hastes sulcadoras de adubo foi medida durante a semeadura direta da soja, safra 2005-2006, a qual foi realizada, utilizando-se de semeadora-adubadora de oito linhas, marca Stara Sfil, modelo SS 8000, com espaçamento entre linhas de 0,45 m. Cada linha de semeadura constituiu-se de um disco de corte de palha, de uma haste sulcadora para a deposição do fertilizante e discos duplos desencontrados para a abertura do sulco onde as sementes foram depositadas à profundidade média de $0,05 \mathrm{~m}$.

A haste em estudo apresenta as seguintes dimensões: 0,415 m comprimento; 0,0127 m largura, e $0,0257 \mathrm{~m}$ de largura da ponteira, com ângulo de ataque de $18^{\circ}$. O trator utilizado foi da marca CBT, modelo 2100, sem tração dianteira auxiliar (TDA), e potência máxima no motor de $77 \mathrm{~kW}(104 \mathrm{cv})$. O conjunto trator/semeadora-adubadora operou à velocidade média de $4,5 \mathrm{~km} \mathrm{~h}^{-1}$. Para a medição dos valores de esforço de tração nas hastes, foram instalados, no suporte de duas linhas, extensômetros de resistência elétrica capazes de medir a deformação ocorrida no suporte quando em operação.

A aquisição de dados foi executada numa freqüência de cinco leituras por segundo, o que equivale, considerando a velocidade de operação utilizada, a um valor medido e armazenado a cada 0,25 m. Os dados foram armazenados por meio de "datalogger" da marca CAMPBEL SCIENTIFIC, modelo CR23X.

Para determinar a área de seção do sulco, utilizou-se de perfilômetro com 0,35 m de largura, equipado com varetas espaçadas de $0,01 \mathrm{~m}$ e curso (deslocamento vertical) de 0,30 m. Também foram realizadas medidas de resistência mecânica do solo à penetração (RP), até a profundidade de 0,30 m, empregando-se um penetrômetro, com características de acordo com ASAE (2004), dotado de sistema eletrônico de medição e aquisição dos dados de força aplicada e a respectiva posição (profundidade) no solo. A metodologia usada na obtenção dessa variável envolveu a realização de 15 leituras por parcela, agrupadas em três transectas. Assim, cada transecta foi composta por cinco leituras executadas lado a lado, espaçadas de $0,4 \mathrm{~m}$.

A umidade gravimétrica $(\mathrm{Ug})$ foi determinada tanto na medição da resistência do solo à penetração, como durante a aquisição dos dados de força de tração, já que as avaliações foram realizadas em dias diferentes.

Por ocasião da semeadura da cultura da soja, determinou-se a massa seca de resíduos da pastagem sobre o solo. Foram retiradas amostras de solo com trado calador para a determinação da massa de raízes até $0,12 \mathrm{~m}$. Em laboratório, essas amostras foram dispersas com hidróxido de sódio $1 \mathrm{M}$, depois foram passadas em peneira com malha de $1 \mathrm{~mm}$, sendo as raízes separadas, lavadas e secas em estufa a $60^{\circ} \mathrm{C}$ e pesadas para a obtenção da massa seca de raízes por volume de solo. 


\section{RESULTADOS E DISCUSSÃO}

Na Tabela 1, são encontrados os valores de massa seca residual da pastagem, que variaram em função dos tratamentos, envolvendo a altura da pastagem mantida no decorrer do período de pastejo. Esses valores indicam tanto a cobertura do solo como a entrada e a ciclagem de nutrientes no sistema. Nas menores alturas, têm-se menor cobertura do solo e menor massa final da pastagem, porém a entrada de biomassa de forragem no sistema foi semelhante ao longo do período de pastejo, haja vista o estímulo representado pelo consumo mais elevado de forragem em função do maior número de animais.

Dessa forma, chega-se à produção final equivalente em todos os tratamentos, mas que, devido ao pastejo, já passou por ciclagem. Devido à menor cobertura sobre o solo nos tratamentos onde foram aplicadas as maiores intensidades de pastejo, também ocorrem perdas mais pronunciadas de água do solo por evaporação; com isso a umidade gravimétrica nesses tratamentos é menor (Figura 1), o que está em concordância com TABOADA (2005).

TABELA 1. Massa seca de resíduos remanescentes da pastagem sobre a superfície e de raízes até $0,12 \mathrm{~m}$ de profundidade.

\begin{tabular}{ccc}
\hline \multirow{2}{*}{ Altura de Pastejo $(\mathrm{m})$} & \multicolumn{2}{c}{ Massa Seca $\left(\mathrm{kg} \mathrm{ha}^{-1}\right)$} \\
\cline { 2 - 3 } & Resíduos & Raízes \\
\hline 0,10 & $2.853 \mathrm{c}$ & $1.468 \mathrm{a}$ \\
0,20 & $3.707 \mathrm{~b}$ & $1.452 \mathrm{a}$ \\
0,30 & $4.175 \mathrm{~b}$ & $1.211 \mathrm{~b}$ \\
0,40 & $4.585 \mathrm{~b}$ & $1.091 \mathrm{~b}$ \\
SP & $5.263 \mathrm{a}$ & $566 \mathrm{c}$ \\
\hline Média & 4.117 & 1.158 \\
\hline C.V. $(\%)$ & 21 & 27
\end{tabular}

Médias seguidas de mesma letra, minúscula nas colunas, não diferem entre si (teste de Duncan, p<0,01).

$\mathbb{N}$ Ug na RP $\quad \boldsymbol{Z} U g$ na semeadura

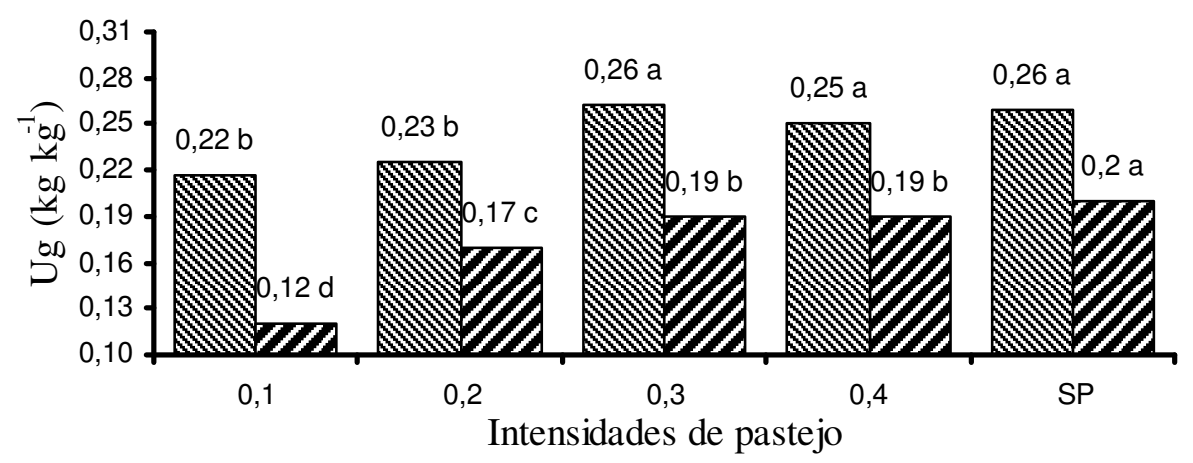

FIGURA 1. Umidade gravimétrica (Ug) no momento da medida da resistência do solo à penetração e na realização da semeadura, nos tratamentos de alturas de pastejo.

Os dados da Tabela 1 mostram ainda que a massa seca de raízes no horizonte superficial aumentou à medida que o pastejo foi intensificado. Nesse sentido, TUBEILEH et al. (2003) relatam que as raízes, ao encontrarem um ambiente desfavorável, como um solo compactado, produzem e enviam, via xilema, sinais bioquímicos, possivelmente constituídos pelo ácido abscísico (ABA). Ao ABA é atribuída diminuição da condutividade dos estômatos, fato que reduz a taxa de assimilação de carbono e, por conseguinte, o crescimento da parte aérea das plantas. Assim, o pastejo mais intenso estimulou o acúmulo de massa seca da parte aérea da pastagem, considerando todo o ciclo de vida da planta, o que resultou num aumento da massa seca de raízes. 
Outro fator que pode explicar os resultados expostos na Tabela 1, relaciona-se à maior compactação subsuperficial do solo, nos tratamentos referentes às menores alturas de pastagem, conforme análise dos valores de resistência à penetração (RP) apresentados na Tabela 2. Diversos trabalhos de pesquisa têm demonstrado que a planta compensa o menor crescimento radicular em profundidade, aumentando o volume de raízes na camada de solo acima da que se encontra compactada (FOLONI et al., 2003; BEUTLER \& CENTURION, 2004). Da mesma forma, o estresse provocado na forrageira pelo pastejo também pode ter estimulado o crescimento radicular (NABINGER, 1999).

$\mathrm{Na}$ Tabela 2, são apresentados os valores de RP determinados nas profundidades de 0,06; 0,$12 ; 0,18 ; 0,24$ e $0,30 \mathrm{~m}$, sob diferentes pressões de pastejo. Nas profundidades de 0,06 e $0,12 \mathrm{~m}$, os menores valores de RP foram obtidos nas parcelas sem pastejo (SP) e naquelas onde a pastagem foi manejada para manter altura de $0,30 \mathrm{~m}$ e $0,40 \mathrm{~m}$. Já na profundidade de $0,18 \mathrm{~m}$, observa-se distinção entre os tratamentos, com menores valores de RP para as menores alturas de pastejo. Além da compactação ocasionada pela maior carga animal nas menores alturas, os valores mais elevados de RP nesses tratamentos podem ser justificados pela umidade gravimétrica mais baixa (Figura 1). Para as profundidades de 0,24 e $0,30 \mathrm{~m}$, os valores médios de RP não diferiram estatisticamente entre si, nem em relação aos obtidos na profundidade de 0,18 m (Tabela 2).

Analisando os dados apresentados na Tabela 2, verifica-se que, mantendo-se a altura da pastagem de inverno superior a $0,20 \mathrm{~m}$, por meio do ajuste da lotação ou carga animal, podem-se manter condições idênticas de solo no que diz respeito ao estado de compactação quando comparada à área sem pastejo, até a profundidade de $0,12 \mathrm{~m}$.

TABELA 2. Resistência mecânica do solo à penetração avaliada em cinco profundidades, nas diferentes alturas de pastejo.

\begin{tabular}{crrrrc}
\hline \multirow{2}{*}{$\begin{array}{c}\text { Altura de } \\
\text { Pastejo (m) }\end{array}$} & \multicolumn{5}{c}{ Resistência do Solo à Penetração (kPa) } \\
\cline { 2 - 6 } & 0,06 & 0,12 & 0,18 & 0,24 & 0,30 \\
\cline { 2 - 6 } & $1.931 \mathrm{a}$ & $5.090 \mathrm{a}$ & $4.340 \mathrm{ab}$ & $4.685 \mathrm{a}$ & $4.340 \mathrm{a}$ \\
0,10 & $1.582 \mathrm{a}$ & $4.488 \mathrm{a}$ & $4.495 \mathrm{a}$ & $4.320 \mathrm{a}$ & $4.206 \mathrm{a}$ \\
0,20 & $940 \mathrm{~b}$ & $3.308 \mathrm{~b}$ & $3.978 \mathrm{abc}$ & $4.081 \mathrm{a}$ & $4.076 \mathrm{a}$ \\
0,30 & $887 \mathrm{~b}$ & $2.994 \mathrm{~b}$ & $3.540 \mathrm{~cd}$ & $3.704 \mathrm{a}$ & $3.630 \mathrm{a}$ \\
0,40 & $760 \mathrm{~b}$ & $2.252 \mathrm{~b}$ & $3.185 \mathrm{~d}$ & $3.717 \mathrm{a}$ & $4.070 \mathrm{a}$ \\
SP & $1.253 \mathrm{~A}$ & $3.725 \mathrm{~B}$ & $3.959 \mathrm{C}$ & $4.107 \mathrm{C}$ & $4.062 \mathrm{C}$ \\
\hline Média & 18 & 14,2 & 7,8 & 9,15 & 8,8 \\
\hline C.V. $(\%)$ & & & \multicolumn{5}{c}{ Profundidades $(\mathrm{m})$} \\
\hline
\end{tabular}

Médias seguidas de mesma letra minúscula nas colunas e maiúscula na linha não diferem entre si (teste de Duncan, $\mathrm{P}<0,01 \%)$.

$\mathrm{Na}$ Tabela 3, observa-se que a força de tração demandada pelas hastes sulcadoras da semeadora aumentou, em média, $120 \%$ quando a profundidade de trabalho passou de $0,12 \mathrm{~m}$ a $0,15 \mathrm{~m}$, enquanto a força de tração específica (FTE, $\mathrm{N} \mathrm{cm}^{-2}$ ) sofreu acréscimo de $82 \%$. Nesse contexto, XAVIER (2005) concluiu que o aumento na profundidade de atuação da haste sulcadora de 0,06 para $0,10 \mathrm{~m}$ incrementou de maneira mais acentuada a FTE (260\%), comparativamente à força de tração por haste (95\%). Possivelmente, o comportamento distinto obtido nesses dois trabalhos é devido às diferenças construtivas dos modelos de hastes utilizadas, bem como o solo e o teor de água no momento da semeadura. A área média de solo mobilizado, por sua vez, foi de $115 \mathrm{e}$ $142 \mathrm{~cm}^{-2}$, respectivamente, para a haste operando a $0,12 \mathrm{~m} \mathrm{e} 0,15 \mathrm{~m}$.

Na Tabela 3, observa-se também que, independentemente da profundidade de trabalho, tanto o esforço de tração por haste quanto a FTE atingiram valores mais elevados nos tratamentos com maior intensidade de pastejo. Uma vez que a área média de solo mobilizado não variou significativamente (C.V. 21,4\%), em função das intensidades de pastejo, o aumento da FTE, quando a pastagem foi manejada sob condições de menor altura, deve-se à maior demanda de força 
de tração pelas hastes sulcadoras de adubo. O aumento no esforço de tração requerido pelas hastes, sob condições de pastejo mais intenso, está relacionado ao maior estado de compactação (Tabela 2) e à menor umidade gravimétrica (Figura 1) do solo nesses tratamentos.

Nesse sentido, o aumento na densidade (SECCO, 2003) e na redução do teor de água do solo (BRAIDA, 2004) incrementam a coesão e o ângulo de atrito interno do solo e, conseqüentemente, a resistência do mesmo ao cisalhamento. Portanto, o pastejo intenso provoca modificações nas características e propriedades físicas do solo numa magnitude suficiente para alterar a força de tração requerida pelas hastes sulcadoras de adubo adaptadas à semeadura direta. Isso fica mais evidente levando-se em consideração que o esforço de tração demandado pelas hastes sulcadoras correlacionou-se positivamente com os valores de RP (Figura 2).

TABELA 3. Força de tração $(\mathrm{N})$ e força de tração específica $\left(\mathrm{N} \mathrm{cm}^{-2}\right)$ na haste sulcadora da semeadora, em função da sua profundidade de trabalho nos tratamentos.

\begin{tabular}{ccccccc}
\hline \multirow{2}{*}{$\begin{array}{c}\text { Altura de pastejo } \\
(\mathrm{m})\end{array}$} & \multicolumn{3}{c}{ Profundidade de atuação da haste sulcadora do adubo (m) } & \multicolumn{3}{c}{ Média } \\
\cline { 2 - 5 } & $\mathrm{N}$ & $\mathrm{N} \mathrm{cm}^{-2}$ & $\mathrm{~N}$ & $\mathrm{~N} \mathrm{~cm}^{-2}$ & $\mathrm{~N}$ & $\mathrm{~N} \mathrm{~cm}^{-2}$ \\
\cline { 2 - 6 } & 2.346 & 22 & 4.874 & 33 & $3.610 \mathrm{a}$ & $28 \mathrm{a}$ \\
0,10 & 2.159 & 18 & 4.487 & 35 & $3.323 \mathrm{ab}$ & $27 \mathrm{a}$ \\
0,20 & 1.915 & 18 & 4.485 & 31 & $3.200 \mathrm{bc}$ & $25 \mathrm{a}$ \\
0,30 & 1.758 & 17 & 3.989 & 30 & $2.873 \mathrm{~cd}$ & $24 \mathrm{a}$ \\
SP & 1.568 & 12 & 3.762 & 24 & $2.665 \mathrm{~d}$ & $18 \mathrm{~b}$ \\
\hline Média & $1.949 \mathrm{~A}$ & $17 \mathrm{~A}$ & $4.319 \mathrm{~B}$ & $31 \mathrm{~B}$ & 3.134 & 24 \\
\hline
\end{tabular}

C.V.(\%) Intensidade de pastejo: força de tração $=8,9 ;$ C.V.(\%) Intensidade de pastejo: força de tração específica $=5,9$ Médias seguidas de mesma letra minúscula nas colunas e maiúscula na linha não diferem entre si (teste de Duncan, $\mathrm{p}<0,01)$.

As equações de regressão mostradas na Figura 2 demonstram que a medição do esforço de tração em hastes sulcadoras pode constituir-se em eficiente ferramenta para estimar, de maneira fácil, rápida e precisa, o estado de compactação do solo. Uma vez que a operação de semeadura esteja georreferenciada, os dados obtidos podem ser utilizados na elaboração de mapas que mostrem a variabilidade espacial do estado de compactação do solo, tendo grande utilidade dentro do contexto da agricultura de precisão, conforme salientam CEPIK et al. (2005). De maneira geral, os valores obtidos, tanto para o esforço de tração, quanto para a FTE com a haste sulcadora da semeadora Stara Sfil, superam os encontrados por CONTE et al. (2005), na mesma área experimental deste estudo, utilizando hastes sulcadoras da semeadora da marca Vence Tudo e também os referidos na norma ASAE 2003 e em BORTOLLOTO et al. (2006). BORDIGNON (2005), trabalhando em Latossolo Vermelho distroférrico (60\% argila), obteve na haste sulcadora da marca John Deere o esforço horizontal de $485 \mathrm{~N}$, na menor profundidade de atuação $(0,08 \mathrm{~m})$, e $2.930 \mathrm{~N}$, na maior profundidade de atuação $(0,18 \mathrm{~m})$, sendo esses valores menores do que os encontrados neste trabalho e presentes na Tabela 2. 


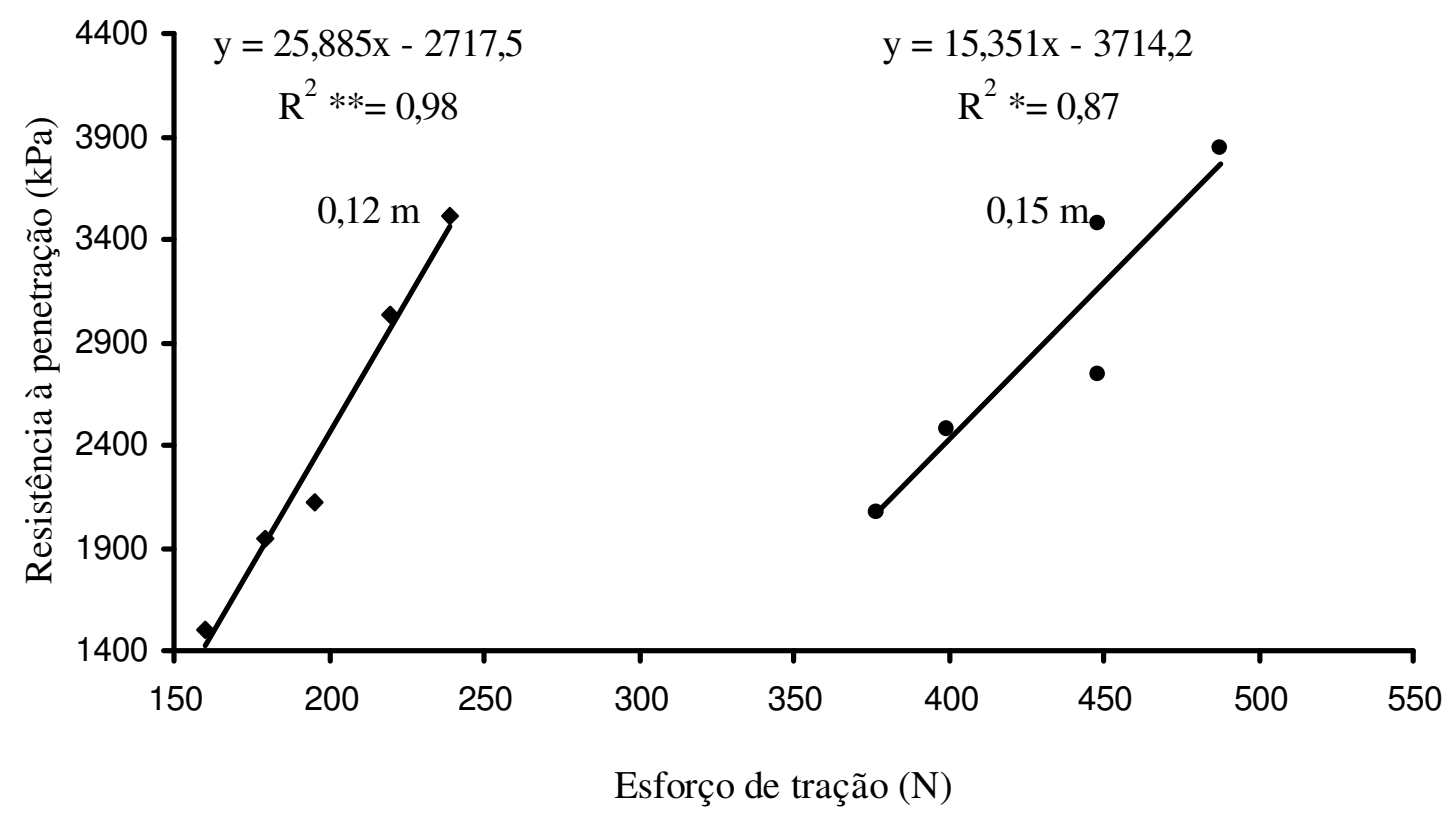

FIGURA 2. Regressão entre os valores de resistência do solo à penetração e esforço de tração, de acordo com a profundidade de atuação da haste sulcadora. ** Significativo a $1 \%$ no teste t. $*$ Significativo a $5 \%$ no teste $\mathrm{t}$.

\section{CONCLUSÕES}

A resistência do solo à penetração permite concluir que o efeito do pastejo foi detectado até a profundidade de $0,18 \mathrm{~m}$, sendo os valores crescentes com a intensidade de pastejo. Os valores de RP medidos no intervalo de profundidade de 0,06 a $0,30 \mathrm{~m}$ podem ser restritivos ao desenvolvimento de culturas anuais. Houve incremento na massa seca de raízes nos tratamentos com maior intensidade de pastejo quando comparado à área sem pastejo (SP), sendo esse aumento também evidenciado nos valores de força de tração demandada nas hastes sulcadoras da semeadora. $\mathrm{O}$ esforço de tração obtido nas hastes sulcadoras correlacionou-se de forma positiva com a resistência do solo à penetração.

\section{REFERÊNCIAS}

ALBUQUERQUE, J.A.; SANGOI, L.; ENDER, M. Efeito da integração lavoura-pecuária nas propriedades físicas do solo e características da cultura do milho. Revista Brasileira de Ciência do Solo, Viçosa, v.25, n.3, p.717-23, 2001.

ASAE. AMERICAN SOCIETY OF AGRICULTURAL ENGINEERS. Soil cone penetrometer ASAE S 313.3. St. Joseph, 2004. 2 p.

ASAE. AMERICAN SOCIETY OF AGRICULTURAL ENGINEERS. Agricultural machinery management data. In: ASAE Standards 2003: standards engineering practices data. St. Joseph: ASAE, 2003. p.373-380.

BERTOL, I.; ALMEIDA, J.A. de; ALMEIDA, E.X. de; KURTZ, C. Propriedades físicas do solo relacionadas a diferentes níveis de oferta de forragem de capim-elefante-anão cv. Mott. Pesquisa Agropecuária Brasileira, Brasília, v.35, n.5, p.1047-54, 2000.

BERTOL, I.; GOMES, K.E.; DENARDIN, R.B.N.; MACHADO, L.A.Z.; MARASCHI, G.E. Propriedades físicas do solo relacionadas a diferentes níveis de oferta de forragem numa pastagem natural. Pesquisa Agropecuária Brasileira, Brasília, v.33, n.5, p.779-86, 1998.

BEUTLER, A.N.; CENTURION, J.F. Compactação do solo no desenvolvimento radicular e na produtividade da soja. Pesquisa Agropecuária Brasileira, Brasília, v.39, n.6, p.581-8 2004. 
BORDIGNON, J. Projeto, construção e desenvolvimento de transdutores para medição de esforços em semeadoras-adubadoras. 2005. 122 f. Dissertação (Mestrado em Engenharia Mecânica) - Escola de Engenharia, Universidade Federal do Rio Grande do Sul, Porto Alegre, 2005.

BORTOLLOTO, C.V.; NETO, P.R.; BORTOLLOTO, C.M. Demanda energética de uma semeadora-adubadora para soja sob diferentes velocidades de deslocamento e coberturas do solo. Engenharia Agrícola, Jaboticabal, v.26, n.1, p.122-30, 2006.

BRAIDA, J.A. Acúmulo de resíduos vegetais na superfície e de matéria orgânica no solo e suas implicações no comportamento mecânico do solo sob plantio direto. 2004. $106 \mathrm{f}$. Tese (Doutorado em Ciência do Solo) - Universidade Federal de Santa Maria, Santa Maria, 2004.

CEPIK, C.T.C.; LEVIEN, R.; TREIN, C.R.; CONTE, O. Compactação do solo em área sob semeadura direta, mapeado por meio de dados de esforço de tração em haste sulcadora de semeadora. In: CONGRESSO BRASILEIRO DE ENGENHARIA AGRÍCOLA, 34., 2005, Canoas. Anais... Jaboticabal: Associação Brasileira de Engenharia Agrícola, 2005. 1 CD-ROM.

CONTE, O.; LEVIEN, R.; TREIN, C.R.; CEPIK, C. Força de tração específica em semeadura direta e resistência do solo à penetração na integração lavoura-pecuária com diferentes pressões de pastejo. In: CONGRESSO BRASILEIRO DE CIÊNCIA DO SOLO, 30., 2005, Recife. Anais... Recife: Sociedade Brasileira de Ciência do Solo, 2005. 1 CD-ROM.

CORREA, J.C.; REICHARDT, K. Efeito do tempo de uso das pastagens sobre as propriedades de um Latossolo Amarelo da Amazônia Central. Pesquisa Agropecuária Brasileira, Brasília, v.30, n.1, p.107-14, 1995.

DEXTER, A.R. Soil physical quality - Part I. Theory, effects of soil texture, density, and organic matter, and effects on root growth. Geoderma, Amsterdam, v.120, n.3-4, p.201-14, 2004.

DIAS JUNIOR, M.S.; PIERCE, F.J. O processo de compactação do solo e sua modelagem. Revista Brasileira de Ciência do Solo, Campinas, v.20, p.175-82, 1996.

EMBRAPA. EMPRESA BRASILEIRA DE PESQUISA AGROPECUÁRIA. Centro Nacional de Pesquisa de Solos. Sistema Brasileiro de classificação de solos. Brasília, 1999. 412 p.

FLORES, J.P.C. Atributos de solo e rendimento de soja em um sistema de integração lavourapecuária com diferentes pressões de pastejo em plantio direto com aplicação de calcário na superfície. 2004. 74 f. Dissertação (Mestrado em Ciência do Solo) - Faculdade de Agronomia, Universidade Federal do Rio Grande do Sul, Porto Alegre, 2004.

FOLONI, J.S.S.; CALONEGO, J.C.; LIMA, S.L. Efeito da compactação do solo no desenvolvimento aéreo e radicular de cultivares de milho. Pesquisa Agropecuária Brasileira, Brasília, v.38, n.8, p.947-53, 2003.

HILLEL, D. Introduction to soil physics. New York: Academic Press, 1982. 364 p.

IMHOFF, S. Indicadores de qualidade estrutural e trafegabilidade de Latossolos e Argissolos Vermelhos. 2002. 94 f. Tese (Doutorado em Solos e Nutrição de Plantas) - Escola Superior de Agricultura "Luiz de Queiroz", Universidade de São Paulo, Piracicaba, 2002.

LEÃO, T.P. Intervalo hídrico ótimo em diferentes sistemas de pastejo e manejo da pastagem. 2002. 58 f. Dissertação (Mestrado em Solos e Nutrição de Plantas) - Escola Superior de Agricultura “Luiz de Queiroz", Universidade de São Paulo, Piracicaba, 2002.

LEVIEN, R. Condições de cobertura e métodos de preparo do solo para a implantação da cultura do milho (Zea mays L.). 1999. 305 f. Tese (Doutorado em Energia na Agricultura) - Faculdade de Ciências Agronômicas, Universidade Estadual Paulista, Botucatu, 1999.

NABINGER, C. Fundamentos básicos do manejo de plantas forrageiras. Notas do módulo 1 da disciplina AGR 05504 - Fisionomia e manejo de pastagens naturais. 1999. 62 p. 
ROSOLEM, C.A.; ALMEIDA, A.C. da S.; SACRAMENTO, L.V.S. do. Sistema radicular e nutrição da soja em função da compactação do solo. Bragantia, Campinas, v.53, n.2, p.259-66, 1994.

SÁNCHEZ-GIRÓN, V. Dinámica y mecânica de suelos. Madrid: Ediciones Agrotécnicas, 1996. $426 \mathrm{p}$.

SÁNCHEZ-GIRÓN, V.; RAMÍREZ, J.J.; LITAGO, J.J.; HERNANZ, J.L. Effect of soil compaction and water content on the resulting forces acting on three seed drill furrow openers. Soil \& Tillage Research, Amsterdam, v.81, n.1, p.25-37, 2005.

SECCO, D. Estados de compactação de dois Latossolos sob plantio direto e suas implicações no comportamento mecânico e na produtividade de culturas. 2003. $108 \mathrm{f}$. Tese (Doutorado em Biodinâmica de Solos) - Universidade Federal de Santa Maria, Santa Maria, 2003.

SOUSA, R.; CAMARGO, F.A.O.; VAHL, L.C. Solos Alagados. In. MEURER, E.J. Fundamentos de química do solo. Porto Alegre: Editora Evangraf, 2006. p.185-210.

TABOADA, M.A. Efectos del pastoreo y pisoteo animal sobre lãs propriedades física de suelos. In: JORAJURÍA COLLAZO, D. (Org.). Reologia del suelo agrícola bajo tráfico: modificaciones fisico-mecánicas del suelo vinculadas a la compactación debida al tráfico agrario. La Plata: Universidad Nacional de La Plata, 2005. p.131-43.

TREIN, C.R.; COGO, N.P.; LEVIEN, R. Métodos de preparo do solo na cultura do milho e ressemeadura do trevo, na rotação aveia + trevo/milho, após pastejo intensivo. Revista Brasileira de Ciência do Solo, Campinas, v.15, n.1, p.105-111, 1991.

TUBEILEH, A.; GROLEAU-RENAUD, V.; PLANTUREUX, S.; GUCKERT, A. Effect of soil compaction on photosynthesis and carbon partitioning within a maize-soil system. Soil \& Tillage Research, Amsterdam, v.71, n.2, p.151-61, 2003.

TULLBERG, J.N. Wheel traffic effects on tillage draught. Journal of Agricultural Engineering Research, Amsterdam, v. 75, n.4, p.375-82, 2000.

XAVIER, A. Comportamento da cultura da soja em função de resíduos culturais, mobilização do solo e irrigação, em semeadura direta. 2005. 99 f. Dissertação (Mestrado em Ciência do Solo) Faculdade de Agronomia, Universidade Federal do Rio Grande Sul, Porto Alegre, 2005. 